\title{
A Cautionary Note on the Put-Call Parity under an Asset Pricing Model with a Lower Reflecting Barrier
}

\author{
Markus Hertrich ${ }^{\mathrm{a}, \mathrm{b}}$
}

\section{JEL-Classification: E52, E58, F31, G13, G15}

Keywords: Euro/Swiss franc floor, hedging, put-call parity, reflected geometric Brownian motion, risk-neutral parity.

\section{Introduction}

The put-call parity, first formalized by STOLL (1969), which will be referred to as the standard put-call parity in this paper, links the value of European put and call options on the same underlying security with the same exercise price and time to maturity in the absence of arbitrage opportunities. It results from a static hedge that mimics the options' payoffs at the maturity date and is therefore free from distributional assumptions. For instance, in the case of geometric Brownian motion (GBM), BlaCK and Scholes (1973) formally demonstrated that in the Black-Scholes option pricing model put and call option prices satisfy the standard put-call parity. It then is tempting to assume that this parity also holds in asset pricing models where the price process of the underlying security follows a GBM with reflecting barriers, a price process that under the risk-neutral measure is a strict local martingale, i.e., a local martingale that does not satisfy the martingale property (see, for instance, ElwORTHY, LI, and Yor, 1999, or CARR, Fisher, and Ruf, 2014, for more details about this class of martingales). However, recent papers have shown that the standard put-call parity does not hold when the underlying price process is a strict local martingale under the risk-neutral probability measure (Cox and Hobson, 2005, and Heston, Loewenstein,

a Department of Finance, University of Basel, Peter Merian-Weg 6, 4052 Basel (Switzerland). Email: markus.hertrich@unibas.ch. I would like to thank Christian Kleiber, Klaus Neusser, Philip Protter, Dirk Veestraeten, Heinz Zimmermann and three anonymous referees for helpful comments and suggestions that improved the initial version. All remaining errors and omissions remain my responsibility. This work is dedicated to Alma Linnéa.

b Institute for Finance, University of Applied Sciences Northwestern Switzerland, Peter MerianStrasse 86, 4002 Basel (Switzerland). Email: markus.hertrich@fhnw.ch. 
and Willard, 2007). To exclude arbitrage opportunities in the sense of the No Free Lunch with Vanishing Risk (NFLVR) ${ }^{1}$ assumption of Delbaen and SchaCHERMAYER (1994) and for the first fundamental theorem of asset pricing to hold (Delbaen and Schachermayer, 1994, and Delbaen and Schachermayer, 1998), risk-neutral valuation must then be justified by invoking constraints on admissible trading strategies such that an equivalent local martingale measure (ELMM) exists (Jarrow, Protter, and Shimbo, 2010). However, the price difference between the risk-neutral put and call prices, which will be denoted as the risk-neutral parity in the following, then no longer corresponds with the standard put-call parity. Hence, two alternative specifications for the relationship between put and call prices arise. ${ }^{2}$

This paper analyzes the put-call parity when reflection is superimposed on GBM, which corresponds to a situation where the martingale property is lost, since the resulting price process follows a submartingale under the risk-neutral measure and according to the definition of a martingale (Dоов, 1971), a martingale is both a sub- and a supermartingale. Consequently, this condition is not fulfilled in the case of a reflected geometric Brownian motion. In the following paragraph and to motivate this paper, first, this paper presents examples in economics and finance where stochastic price processes with reflecting barriers arise. Second, it is explained why it is interesting to analyze options in these cases and in particular, why it is important to analyze the relationship between both parities.

Veestraeten (2008) examined GBM with reflection within the context of a takeover bid where the prospective conversion price acts as a lower boundary ${ }^{3}$ for the stock price. Portfolio insurance products with a continuously guaranteed floor level of protection (see Gerber and Pafumi, 2000, Imai and Boyle, 2001, and Ko, SHIU, and WeI, 2010, among others) also generates reflecting barriers, as well as when regulatory maximum prices or (agricultural) floor prices exist (see, for instance, Shonkwiler and Maddala, 1985). Furthermore, reflecting barriers emerge within exchange rate target zones in which authorities prevent the exchange rate from moving beyond some level. The Japanese monetary authorities, for instance, have actively intervened to combat appreciations of the

1 In financial markets that satisfy the NFLVR assumption, where the wealth process exhibits a lower barrier and where always a non-negative final wealth results that can be strictly positive with a positive probability, trading strategies that start with zero initial wealth are precluded (Ruf, 2013).

2 Moreover, if the market satisfies the NFLVR condition and financial markets are complete, then the ELMM is unique (Jarrow, Protter, and Shimbo, 2007).

3 Notice that in this paper the term barrier and boundary are used interchangeably. 
yen vis-à-vis the US dollar (see, for instance, Chaboud and Humpage, 2005) and as such created a reflecting lower barrier. ${ }^{4}$ Switzerland is another and recent example, where the Swiss National Bank (SNB) introduced a lower boundary for the EUR/CHF exchange rate on September 6, 2011 (Swiss National Bank, 2011), which the SNB finally abandoned on January 15, 2015.

All these examples show that GBMs with reflecting barriers arise in several areas of economic and financial theory, as well as in empirical work. Moreover, in all of these examples, it is possible to write put and call options on the respective underlying security, (possibly) adding completeness to the respective market and allowing a more efficient risk transfer. Therefore, the present analysis of the put-call parity that arises when reflection is superimposed on GBM is an important contribution to this strand of literature. In this respect, the contribution of this paper is the following: First, it is demonstrated that the martingale property is lost when reflection is superimposed on GBM and that, here also, at least two different expressions emerge for the relationship between put and call prices; i.e., the standard put-call parity and the risk-neutral parity.

Second, although both parities can coexist when the martingale property is lost due to the NFLVR assumption, in the sense that more than one option price may solve the partial differential equation (PDE) in the Black-Scholes setting, one should choose either the no-arbitrage relation implied by the standard putcall parity or the no-arbitrage relation implied by risk-neutral option pricing (Heston, Loewenstein, and Willard, 2007). However, there are studies in academia that erroneously mix both parities in a risk-neutral pricing framework when the diffusion is bounded by reflecting barriers (see, for instance, CAMPA and Chang, 1996, Ingersoll Jr., 1997 and Veestraeten, 2008). Therefore, in order to assess the relevance of the error that some academic papers (potentially) incurred by wrongly mixing both parities, the size and nature of the difference between both parities is analyzed as a cautionary note.

Third, the risk-neutral parity that is derived for a reflected geometric Brownian motion is used to analyze the impact that the introduction of a boundary in an initially free floating exchange rate system has on foreign exchange (FX) hedging costs. Specifically, it is analyzed how this policy change impacts the costs of a risk reversal, a commonly used hedging strategy in FX markets that is derived from

4 Further examples include the Swedish Riksbank from 1993-2002 (Humpage and Ragnartz, 2006), the Swiss National Bank in 1978, the Croatian National Bank in 1993 (Cottarelli and Doyle, 1999) or similarly the Czech National Bank since November 7, 2013 (Czech National Bank, 2013). 
the standard put-call parity. An empirical application to the EUR/CHF ${ }^{5} 1.20$ minimum exchange rate regime that the SNB implemented from September 6, 2011 to January 15, 2015 shows that investors who used the Swiss franc as their numéraire and sought protection against a weakening euro incurred substantial costs as a result of hedging exposure to the euro and may have been overexposed to FX risk in this period.

Fourth and as a side effect of the main analysis, this paper offers an alternative explanation for the existence of EUR/CHF put options with exercise prices below the EUR/CHF 1.20 floor that traded at non-zero cost in the analyzed period, even if investors perceived the minimum exchange rate policy of the SNB visà-vis the euro currency as fully credible. It is shown that under an asset pricing model where the exchange rate follows a reflected geometric Brownian motion such put options can indeed have positive prices, whenever investors erroneously apply the standard put-call parity in a risk-neutral pricing framework to impute put prices from call prices. This observation shows how, for instance, risk-neutral investors can generate bubbles in derivatives markets, ${ }^{6}$ which may cause financial instability. Hence, the possibility of (at least theoretically possible) destabilizing price bubbles in FX options markets and the aforementioned examples that show that mixing both parities is also done in academia underlines the necessity of the present cautionary note.

The remainder of this chapter is organized as follows. Section 2.1 summarizes some well-known results on option pricing and develops the put-call parity under GBM. In Section 2.2, a reflecting barrier is superimposed on GBM, the option prices that result under the risk-neutral measure are derived and it is confirmed that two expressions emerge for the relationship between put and call option prices. In Section 2.3, the impact that different parameters have on the difference between both parities is illustrated, or the error that arises when using the standard put-call parity in a risk-neutral pricing framework as a shortcut to impute put prices from call prices, and vice versa. In Section 3, this paper empirically illustrates for the case of the EUR/CHF FX rate under the SNB's recently abandoned minimum exchange rate regime how both parities can be used to assess the impact that the introduction of a floor in FX markets has on hedging costs. Section 4 summarizes the main findings of this paper.

5 Although the exchange rate is analyzed from a CHF perspective in this paper, i.e., the number of units of Swiss francs needed to buy one euro or a floor of 1.20 Swiss francs per euro, respectively, the exchange rate is referred to as "EUR/CHF" in the body of the text, following the FX market convention (see ReIswich and Wystup, 2010, among others).

6 See, e.g., the risk-neutral valuation paradox in MACCIONI (2011) for an alternative explanation of how investors can create bubbles in derivatives markets. 


\section{The Put-Call Parity}

\subsection{The Put-Call Parity under Geometric Brownian Motion}

Assume that before the implementation of the strong-side commitment, the spot exchange rate ${ }^{7} S_{t}$ (quoted as the number of units of domestic currency required to buy one unit of foreign currency as of time $t$ ) follows a $\mathrm{GBM}^{8}$ in a free floating exchange rate regime with drift coefficient $\mu$ and diffusion coefficient $\sigma$ :

$$
d S_{t}=\mu S_{t} d_{t}+\sigma S_{t} d W_{t}
$$

where $d W_{t}$ denotes the increment of a standard Wiener process. The free-floating exchange rate is a martingale if the drift coefficient $\mu$ in Equation (1) is replaced by

$$
\mu=r-r^{f},
$$

where $r$ and $r^{f}$ are the instantaneous, continuously compounded risk-free interest rates in the domestic and foreign currency, respectively.

Under the risk-neutral valuation approach (Cox and Ross, 1976), the price of a European call option on the spot exchange rate $S_{t}$ with an exercise price $X$ and a time to maturity $\tau=T-t$ can be expressed as (Garman and KohlHagen, 1983):

$$
\begin{aligned}
C\left(X, S_{t}, r, r^{f}, \sigma, \tau\right)_{t} & =\exp ^{-r \tau} \int_{X}^{\infty}\left(S_{T}-X\right) \operatorname{pr}\left(S_{T}, S_{t}, r, r^{f}, \sigma, \tau\right) d S_{T} \\
& =S_{t} \exp ^{-r_{\tau}} \Phi\left(z_{1}\right)-X \exp ^{-r \tau} \Phi\left(z_{1}-\sigma \sqrt{\tau}\right),
\end{aligned}
$$

with

$$
z_{1}=\frac{\ln \left(\frac{S_{t}}{X}\right)+\left(r-r^{f}+\frac{\sigma^{2}}{2}\right) \tau}{\sigma \sqrt{\tau}},
$$

7 Alternatively, the following formulas can be applied to stock prices, assuming a perpetual flow of dividends proportional to the level of the contemporaneous stock price.

8 This is a commonly used assumption in finance, see, e.g. Glasserman (2004), Wystup (2010a), Musiela and Rutkowski (2009) or Geman (2015). 
where $\operatorname{pr}\left(S_{T}, S_{t}, r, r^{f}, \sigma, \tau\right)$ and $\Phi(\cdot)$ denote the risk-neutral transition density function and the cumulative distribution function of the standard normal distribution, respectively.

The corresponding put price can accordingly be expressed as (GARMAn and Kohlhagen, 1983):

$$
\begin{aligned}
P\left(X, S_{t}, r, r^{f}, \sigma, \tau\right)_{t} & =\exp ^{-r \tau} \int_{0}^{X}\left(X-S_{T}\right) \operatorname{pr}\left(S_{T}, S_{t}, r, r^{f}, \sigma, \tau\right) d S_{T} \\
& =X \exp ^{-r \tau} \Phi\left(-z_{2}\right)-S_{t} \exp ^{-r^{f} \tau} \Phi\left(-z_{1}\right),
\end{aligned}
$$

with

$$
z_{2}=\frac{\ln \left(\frac{S_{t}}{X}\right)+\left(r-r^{f}-\frac{\sigma^{2}}{2}\right) \tau}{\sigma \sqrt{\tau}}=z_{1}-\sigma \sqrt{\tau} .
$$

The risk-neutral put price can also be obtained from the call price in Equation (3) together with the standard put-call parity. In fact, STOLL (1969) showed that the relationship between call and put prices can be derived from a static hedge in which a call is sold and a put is bought, with both options having the same exercise price and time to maturity. Completing this portfolio by borrowing $\left\{X \cdot \exp ^{-r \tau}\right\}$ units of domestic money and lending $\left\{1 \cdot \exp ^{-r f_{\tau}}\right\}$ units of foreign money then guarantees that its payoff at time $T$ is zero. In order to ensure that this portfolio is not dominated nor dominates (MerTon, 1973), its value at time $t$ then must also equal zero. Hence, the following expression for the putcall parity results:

$$
\begin{aligned}
P C P & \equiv P\left(X, S_{t}, r, r^{f}, \sigma, \tau\right)_{t}-C\left(X, S_{t}, r, r^{f}, \sigma, \tau\right)_{t} \\
& =X \exp ^{-r \tau}-S_{t} \exp ^{-r_{\tau}} .
\end{aligned}
$$

Indeed, plugging the call price in Equation (3) into Equation (5) yields the put price in Equation (4). In other words, the standard put-call parity under GBM yields exactly the difference between the risk-neutral put and call prices. 


\subsection{The Put-Call Parity under Geometric Brownian Motion with Reflection}

Now assume that the domestic central bank introduces a (temporary) unilateral (in the following, this term will be omitted for the sake of simplicity) one-sided target zone for the exchange rate $S_{t}$ subject to a lower boundary $b$, whereby a central bank intervenes to buy a specific foreign currency to maintain a minimum exchange rate $b$ (which will be called "floor" in the following), such that it can guarantee a minimum exchange rate $b$. Hence, the then observed exchange rate $\tilde{S}_{t}$ will be equal to or larger than the formerly free floating and now (partially) latent (or shadow) exchange rate $S_{t}$. The observed exchange rate $\tilde{S}_{t}$ then equals:

$$
\tilde{S}_{t}=S_{t} \cdot \max \left\{1, \max _{0 \leq s \leq t}\left(\frac{b}{S_{s}}\right)\right\} \text {. }
$$

Scaling the stochastic process $\tilde{S}_{t}$ by the floor $b$ and taking logs, the resulting stochastic process $\left\{\ln \left(\tilde{S}_{t} / b\right)\right\}$ results from the (scaled) exchange rate process $\left\{\ln \left(S_{t} / b\right)\right\}$ in a free-floating exchange rate regime by introducing a reflecting barrier at zero, ${ }^{9}$ a so-called reflected (or regulated) GBM (RGBM): ${ }^{10}$

$$
d S_{t}=\left(r-r^{f}\right) \cdot S_{t} d_{t}+\sigma S_{t} d W_{t}+S_{t} d L_{t},
$$

where the process $L_{t}$ is the so-called reflection function in Sковокнор (1961). $L_{t}$ is a continuous, non-decreasing process with $L_{0}=0$ and increases only when $S_{t}$ hits the lower barrier $b$ (see, e.g., HARRISON (1985)). In that case reflection takes place instantaneously. This reflection mechanism ensures that the exchange rate does not spend finite time on the barrier, such that no situation can arise in which the exchange rate could only move in one direction, hereby enabling riskless arbitrage gains (see, e.g., Ingersoll JR., 1987, p.270, or Bergman, 1996, for more details about this statement). For more details on the reflection mechanism and its implications for option pricing, the interested reader is referred to Veestraeten (2008).

9 See, e.g., Veestraeten (2013), Hertrich and Zimmermann (2015) or Gerber and Pafumi (2000) and Ko, Shiu, and Wei (2010) for a similar approach applied to the price process of an investment fund.

10 Being consistent with the commonly used assumption that exchange rates follow a GBM (see footnote 8 ), a RGBM results by superimposing instantaneous and infinitesimal reflection at the lower barrier $b$ on GBM. 
The RGBM in Equation (7) implies that the drift rate of $\tilde{S}_{t}$ is identical to the drift rate $\mu$ of $S_{t}$. Let $S_{0}>b$ denote the initial exchange rate, i.e., the exchange rate that is observed in the market just after announcing the introduction of a lower floor level for the exchange rate $S_{t}$. Hence, initially $\tilde{S}_{0}$ equals $S_{0}$ and $\tilde{S}_{t} \geq S_{t}$ for $t>0$, whereby assuming that the latent exchange rate $S_{t}$ is the "fair" equilibrium exchange rate, the domestic currency will be either "fairly" priced or undervalued with respect to the foreign currency (similar to the case in Hertrich and Zimmermann (2015), Jermann (2014) and Hanke, Poulsen, and Weissensteiner (2015)) under the strong-side commitment. In terms of the strand of literature about asset price bubbles, this implies that the observed exchange rate $\tilde{S}_{t}$ now has a non-negative bubble, ${ }^{11}$ which will become relevant in the empirical application. In terms of the stochastics of the RGBM, $\tilde{S}_{t}$ now constitutes a semimartingale (Dhrymes, 1998), since it can be decomposed into a local martingale and two finite variation processes, namely the drift and the reflection component. For $\ln \left(S_{t}\right)$, Equation (7) becomes:

$$
d \ln \left(S_{t}\right)=\left(r-r^{f}-\frac{\sigma^{2}}{2}\right) d_{t}+\sigma d W_{t}+d L_{t}
$$

With regards to the martingale property of the RGBM, notice the following analogy: According to Equations (7) or (8), the conditional expectation of $\left\{\ln \left(\tilde{S}_{t} / b\right)\right\}$ can be obtained from $\left\{\ln \left(S_{t} / b\right)\right\}$ by introducing a reflecting barrier at zero (Gerber and Pafumi, 2000). Hence, the conditional expectation under RGBM $\mathrm{E}_{r}\left(S_{T}, S_{t}, r, r^{f}, \sigma, \tau, b\right)_{t}$ in Appendix A equals the conditional expectation of $\tilde{S}_{t}$ under the minimum exchange rate regime. As reflection can only add value (see also Subsection 2.3), it follows that:

$$
\mathrm{E}_{r}\left(S_{T}, S_{t}, r, r^{f}, \sigma, \tau, b\right)_{t}>\mathrm{E}\left(S_{T}, S_{t}, r, r^{f}, \sigma, \tau\right)_{t}=S_{t} \exp ^{\mu \tau}, \text { for } b>0,
$$

where the second conditional expectation equals the expected value for $S_{t}$ under GBM. Moreover, as long as $\tilde{S}_{t}$ is not reflected at the lower barrier $b, \tilde{S}_{t}=S_{t}$ holds (see Gerber and Pafumi, 2000, and Imai and Boyle, 2001). Hence, $\mathrm{E}_{r}\left(S_{T}, S_{t}, r, r^{f}, \sigma, \tau, b\right)_{t} \geq \tilde{S}_{t} \exp ^{\mu \tau}$, whereby the price process $\tilde{S}_{t}$ now follows a submartingale under the risk-neutral measure (Dоoв, 1971). Therefore, $\tilde{S}_{t}$ is

11 According to the classification in Jarrow, Protter, and Shimbo (2007), this bubble would be a so-called type 3 bubble. 
a local martingale that does not satisfy the martingale property. The latent exchange rate $S_{t}$, however, still follows a martingale (see Subsection 2.1) as it is the case in Hertrich and Zimmermann (2015) or as implicitly assumed in Jermann (2014) and Hanke, Poulsen, and Weissensteiner (2015). Notice that in the following the observed exchange rate will be denoted by $S_{t}$, given that under the minimum exchange rate regime $\tilde{S}_{0}=S_{0}$ and given that the changes in $\tilde{S}_{t}$ can be modeled as in Equation (7).

In the following, it is assumed that the exercise price is located above the barrier, i.e., $X>b$. The results for the case $X<b$ are derived in Appendix B. The following transition density $\operatorname{pr}_{r}\left(S_{T}, S_{t}, r, r^{f}, \sigma, \tau, b\right)$ gives the likelihood of reaching the exchange rate level $S_{T}$ at time $T$ out of the source point $\left(S_{t}, t\right)$, given that $b$ is a reflecting boundary. Adjusting the transition density in Veestraeten (2008) by introducing a perpetual dividend yield for stocks, which is equivalent to a constant, continuously compounded interest rate on the foreign currency, the corresponding density for an exchange rate as the underlying security equals (Hertrich and Zimmermann, 2015):

$$
\begin{aligned}
\operatorname{pr}_{r}(\cdot, b) \equiv & \operatorname{pr}_{r}\left(S_{T}, S_{t}, r, r^{f}, \sigma, \tau, b\right) \\
= & \frac{\left\{\exp -\frac{\mid \ln \left(\frac{S_{T}}{S_{t}}\right)-\left(r-r^{f}-\frac{\sigma^{2}}{2}\right) \tau^{2}}{2 \sigma^{2} \tau}+\exp \frac{\ln \left(\frac{b}{S_{t}}\right)\left(2\left[r-r^{f}\right]-\sigma^{2}\right)}{\sigma^{2}} \exp -\frac{\left|\ln \left(\frac{S_{T} S_{t}}{b^{2}}\right)-\left(r-r^{f}-\frac{\sigma^{2}}{2}\right) \tau^{2}\right|}{2 \sigma^{2} \tau}\right\}}{\sigma S_{T} \sqrt{2 \pi \tau}} \\
& -\frac{\left(2\left[r-r^{f}\right]-\sigma^{2}\right)}{S_{T} \sigma^{2}} \exp \frac{\ln \left(\frac{S_{T}}{b}\right)\left(2\left[r-r^{f}\right]-\sigma^{2}\right)}{\sigma^{2}} \\
& \cdot\left\{1-\Phi\left(\frac{\ln \left(\frac{S_{T} S_{t}}{b^{2}}\right)+\left(r-r^{f}-\frac{\sigma^{2}}{2}\right) \tau}{\sigma \sqrt{\tau}}\right)\right\} .
\end{aligned}
$$

Decreasing $b$ to zero simplifies Equation (10) and the risk-neutral transition density function under GBM results, as reflection is precluded, given that zero is not accessible under GBM.

Under the RGBM assumption, risk-neutral valuation then gives the following expression for the call price (see also VeEstraeten (2013)): 


$$
\begin{aligned}
C_{r}(\cdot, b)_{t} & \equiv C_{r}\left(X, S_{t}, r, r^{f}, \sigma, \tau, b\right)_{t} \\
& =\exp ^{-r \tau} \int_{X}^{\infty}\left(S_{T}-X\right) p r_{r}(\cdot, b) d S_{T}, \\
& =S_{t} \exp ^{-r^{f} \tau} \Phi\left(z_{1}\right)-X \exp ^{-r \tau} \Phi\left(z_{1}-\sigma \sqrt{\tau}\right) \\
& +\frac{1}{\theta}\left\{S_{t} \exp ^{-r^{f} \tau}\left(\frac{b}{S_{t}}\right)^{1+\theta} \Phi\left(z_{3}\right)-X \exp ^{-r \tau}\left(\frac{X}{b}\right)^{\theta-1} \Phi\left(z_{3}-\theta \sigma \sqrt{\tau}\right)\right\},
\end{aligned}
$$

with

$$
\begin{aligned}
\theta & =2 \frac{\left(r-r^{f}\right)}{\sigma^{2}} \\
z_{3} & =\frac{\ln \left(\frac{b^{2}}{X S_{t}}\right)+\left(r-r^{f}+\frac{\sigma^{2}}{2}\right) \tau}{\sigma \sqrt{\tau}} .
\end{aligned}
$$

As required, removing the reflecting barrier $(b=0)$ simplifies the call price under RGBM, and the call price in Equation (3) results. The corresponding risk-neutral put price under RGBM equals (Hertrich and Veestraeten, 2013):

$$
\begin{aligned}
P_{r}(\cdot, b)_{t} & \equiv P_{r}\left(X, S_{t}, r, r^{f}, \sigma, \tau, b\right)_{t} \\
& =\exp ^{-r \tau} \int_{b}^{X}\left(X-S_{T}\right) p r_{r}(\cdot, b) d S_{T} \\
& =X \exp ^{-r \tau} \Phi\left(-z_{1}+\sigma \sqrt{\tau}\right)-b \exp ^{-r \tau} \Phi\left(z_{4}\right) \\
& -S_{t} \exp ^{-r^{f} \tau}\left\{\Phi\left(-z_{4}+\sigma \sqrt{\tau}\right)-\Phi\left(z_{1}\right)\right\} \\
& -\frac{1}{\theta}\left\{\begin{array}{l}
S_{t} \exp ^{-r^{f} \tau}\left(\frac{b}{S_{t}}\right)^{1+\theta} \cdot\left[\Phi\left(z_{4}+\theta \sigma \sqrt{\tau}\right)-\Phi\left(z_{3}\right)\right]-b \exp ^{-r \tau} \Phi\left(z_{4}\right) \\
+X \exp ^{-r \tau}\left(\frac{X}{b}\right)^{\theta-1} \Phi\left(z_{3}-\theta \sigma \sqrt{\tau}\right)
\end{array}\right\},
\end{aligned}
$$


with

$$
z_{4}=\frac{\ln \left(\frac{b}{S_{t}}\right)-\left(r-r^{f}-\frac{\sigma^{2}}{2}\right) \tau}{\sigma \sqrt{\tau}} .
$$

Again, removing the reflecting barrier $(b=0)$ simplifies the put price under RGBM, and the put price in Equation (4) results.

The put price in Equation (12) for a stock with no dividends was not documented in Veestraeten (2008), as he assumed that it could be obtained from the call price via the standard put-call parity. This belief found its origin in the fact that the static hedge of STOLL (1969) continues to give the standard expression for the put-call parity. Indeed, reflection does not create intermediate payments, does not cancel option contracts or alter their payoff, such that Table 1 corresponds to the contingent payoffs that is implied by the standard put-call parity in the case of GBM (see Subsection 2.1):

Table 1: Value of the Investment Positions in the Static Hedge Argument of STOLL (1969) when Reflection is Possible.

\begin{tabular}{c|cc}
\hline Value at time $t$ & $S_{T}>X$ & Value at time $T$ \\
& $-\left(S_{T}-X\right)$ & $S_{T}<X$ \\
\hline$C_{t}^{*}$ & 0 & $+\left(X-S_{T}\right)$ \\
$-P_{t}^{*}$ & $-X$ & $-X$ \\
$+X \exp ^{-r \tau}$ & $+S_{T}$ & $+S_{T}$ \\
$-S_{t} \exp ^{-r f_{\tau}}$ & 0 & 0 \\
0 & & \\
\hline
\end{tabular}

Notes: The table shows the static hedge argument of Stoll (1969) who shows that the relationship between the market prices of call options $C_{t}^{*}\left(X, S_{t}, r, r^{f}, \sigma, \tau, b\right)_{t}$ and put options $P_{t}^{*}\left(X, S_{t}, r, r^{f}, \sigma, \tau, b\right)_{t}$, abbreviated by $C_{t}^{*}$ and $P_{t}^{*}$, respectively, can be derived from a static hedge portfolio, i.e., a portfolio in which a call is sold, a put is bought with both options having the same exercise price $X$ and time to maturity $\tau$ by borrowing $\left\{X \cdot \exp ^{-r \tau}\right\}$ units of domestic money and lending $\left\{1 \cdot \exp ^{-r^{f} \tau}\right\}$ units of foreign money, guaranteeing a payoff of zero at time $T$, when reflection is possible. To ensure that this portfolio is not dominated nor dominates (Merton, 1973), its value at time $t$ then also must be zero. 
However, now two distinct expressions for the relationship between put and call prices emerge, since the risk-neutral put-call parity under reflection is not identical to the standard put-call parity PCP in Equation (5) (notice that $\mathrm{E}_{r}\left(S_{T}, S_{t}, r, r^{f}, \sigma, \tau, b\right)_{t} \exp ^{-r \tau} \neq S_{t} \exp ^{-r f_{\tau}}$, see Appendix A):

$$
\begin{aligned}
P C P_{r}^{R N V} \equiv & P_{r}(\cdot, b)_{t}-C_{r}(\cdot, \tau, b)_{t}, \\
= & X \exp ^{-r \tau}-S_{t} \exp ^{-r_{\tau}} \Phi\left(-z_{4}+\sigma \sqrt{\tau}\right) \\
& -b \exp ^{-r \tau}\left\{\Phi\left(z_{4}\right)-\left(\frac{1}{\theta}\right) \Phi\left(z_{4}\right)\right\} \\
& -\frac{1}{\theta}\left\{S_{t} \exp ^{-r^{f} \tau}\left(\frac{b}{S_{t}}\right)^{1+\theta} \Phi\left(z_{4}+\theta \sigma \sqrt{\tau}\right)\right\} \\
& =X \exp ^{-r \tau}-\mathrm{E}_{r}\left(S_{T}, S_{t}, r, r^{f}, \sigma, \tau, b\right)_{t} \exp ^{-r \tau},
\end{aligned}
$$

such that according to the standard PCP arbitrage opportunities arise.

This observation is in accordance with, for instance, the results in Cox and Hobson (2005) or Heston, Loewenstein, and Willard (2007), who both show that the relationship between put and call prices indeed is not unique when the martingale property is lost for the underlying security, as in the present case of RGBM. In other words, although an ELMM exists, the martingale restriction in LONGSTAFF (1995) does not hold for the risk-neutral transition density $\operatorname{pr}_{r}(\cdot, b)$. This is due to the fact that in this case the risk-neutral measure is not a martingale measure and that consequently the valuation PDE yields more than one solution, depending on whether the currency options are priced under the risk-neutral measure developed in VeESTRAETEN (2008) and adjusted for currencies as in Hertrich and Zimmermann (2015), or whether the standard put-call parity is used to impute call (put) option prices from the corresponding put (call) option prices. Indeed, depending on the restrictions imposed on admissible trading strategies (e.g., whether short-selling is possible) under the NFLVR condition, there may be more than just two alternative option prices that solve the valuation PDE. Hence, some solutions may satisfy, for instance, the put-call parity, although they do not correspond with the option prices under the risk-neutral measure.

At this point, it is necessary to make the following remark: As a put option is a conditional claim with a bounded payoff, it can be shown (see MAdAN and Yor (2006), Екström and Tysк (2009) or Protter (2013) for a proof) that also in cases where the martingale property is lost, such that non-negative asset price 
bubbles are possible, the put price is unique and equals the risk-neutral put price. However, the same does not hold for call options, whereby multiple call prices arise, depending, for instance, on the no-arbitrage condition involved (i.e., the call price according to the standard PCP or the risk-neutral measure). Notice that a non-negative price bubble in the case of an exchange rate, when using one currency as the numéraire, results in a non-negative price bubble when expressing the spot exchange rate in the other numéraire currency (CARR, FISHER, and RUF, 2014) or in a negative bubble if, for instance, the domestic risk-neutral measure is also used for a foreign investor (JARRow and Protter, 2011). ${ }^{12}$ Consequently, by the foreign-domestic equivalence (GRABBE, 1983), the non-uniqueness of the call price when the underlying is $S_{t}$ implies the non-uniqueness of the put price when the underlying is $S_{t}^{-1}$. Accordingly, the uniqueness of the put price when the underlying is $S_{t}$ implies the uniqueness of the call price when the underlying is the inverse of the exchange rate $S_{t}^{-1}$.

What is the intuition behind this remark? For that purpose, let us elaborate on the notion of an asset price bubble (or in short, a bubble). In general, a bubble is defined as the difference between the asset's market price and the replicating strategy with the lowest cost or its fundamental value (see, e.g., Heston, Loewenstein, and Willard (2007) or Protter (2013)). A bubble can be modeled by an underlying security whose discounted price process is a strict local martingale under a given pricing measure (ЕкsтRöм and TYsк, 2009). In particular, it can be shown that the risk-neutral price corresponds to the lowest cost replicating strategy with non-negative value (Heston, Loewenstein, and Willard, 2007). Similarly, Protter (2013) defines the fundamental value as the asset price that is calculated under the risk-neutral measure. Consequently, an asset pricing bubble equals the asset's market price minus the corresponding risk-neutral price.

Now suppose that the put option has a non-negative price bubble. This is only possible if the put price exceeds the exercise price $X$ with positive probability (Heston, Loewenstein, and Willard, 2007). Given that put prices are bounded by the discounted exercise price, the bubble must always equal zero. Hence, put prices should always be unique and equal the risk-neutral price. In addition, due to the NFLVR assumption an ELMM exists (JARROw and Protter, 2007). Therefore, the risk-neutral put price can easily be obtained using the risk-neutral density in Equation (10).

12 Shiller (2000) or Dillén and Sellin (2003), for instance, both document the existence of negative price bubbles in recent episodes. 
What about call option prices? In this paper, a reflecting boundary is superimposed on GBM and the martingale property is lost, since in this case a submartingale results. Compared to the exchange rate that would prevail without the minimum exchange rate, the domestic central bank might have created a non-negative bubble (see Equation (6)). Indeed, under the target zone regime, we are dealing with a submartingale, a local martingale that does not satisfy the martingale restriction. Consequently, the underlying security will exhibit a bubble. The fact that the put-call parity holds for fundamental prices, irrespective of the existence of asset pricing bubbles (РRоTтER, 2013) and assuming that the standard put-call parity holds, implies that the sum of the put option bubble and the discounted bubble (at the foreign interest rate $r^{f}$ ) on the underlying security must equal the bubble on the call (Heston, Loewenstein, and Willard, 2007). Since the put option bubble is zero, the call price must have a non-negative bubble that is equal to the bubble on the underlying security. Hence, due to the existence of the call option bubble, the call price will not equal its risk-neutral price.

However, due to the aforementioned NFLVR assumption, an ELMM exists. Therefore, a risk-neutral call price can be calculated as well, which equals its fundamental value. Consequently, the call market price can take on at least these two values, i.e., the risk-neutral call price and the imputed call price via the standard put-call parity. While under the target zone regime the strategy of short-selling the foreign currency and investing the proceeds in a cheaper replicating strategy (i.e., according to the standard PCP) might result in a large profit when the minimum exchange rate policy is abandoned, there are, nevertheless, no-arbitrage opportunities to exploit, since this arbitrage portfolio is exposed to possibly unbounded losses before unwinding the short position at maturity (e.g., due to margin requirements). Hence, this trading strategy is not admissible under the NFLVR assumption (see, e.g., Pennacchi (2008) and Ruf (2013)).

\subsection{The Standard PCP vs. the Risk-Neutral PCP}

In the following, the size and nature of the difference between the two put-call parities in absolute terms will be illustrated via the metric $\Delta_{r}$, which in this section is defined as the risk-neutral put-call parity under reflection minus the relationship between the market put and call prices implied by the standard putcall parity: 


$$
\begin{aligned}
\Delta_{r} & =P C P_{r}^{R N V}-P C P, \\
& =S_{t} \exp ^{-r^{f} \tau} \Phi\left(z_{4}-\sigma \sqrt{\tau}\right)-b \exp ^{-r \tau}\left\{\Phi\left(z_{4}\right)-\left(\frac{1}{\theta}\right) \Phi\left(z_{4}\right)\right\} \\
& -\frac{1}{\theta}\left\{S_{t} \exp ^{-r^{f} \tau}\left(\frac{b}{S_{t}}\right)^{1+\theta} \Phi\left(z_{4}+\theta \sigma \sqrt{\tau}\right)\right\}, \\
& =S_{t} \exp ^{-r^{f} \tau}-\mathrm{E}_{r}(\cdot, b) \exp ^{-r \tau}, \\
& =\exp ^{-r \tau}\left\{\mathrm{E}\left(S_{T}, S_{t}, r, r^{f}, \sigma, \tau\right)-\mathrm{E}_{r}(\cdot, b)\right\} .
\end{aligned}
$$

Figure 1 depicts $\Delta_{r}$ for the baseline scenario (the solid lines in Figure 1) with the parameter values $b=1.20, X=1.25, r=0.05 \%, r^{f}=1.05 \%, \sigma=10 \%$ and $\tau=1$. The dotted lines in panels (1)-(4) show $\Delta_{r}$ for larger values of the parameters $\tau, r, \sigma$ and $X$, respectively, in order to shed light on the underlying determinants of the difference.

As required, the difference vanishes for a higher exchange rate in view of the lower distributional and thus pricing impact of $b$. Moreover, notice that the metric $\Delta_{r}$ is always non-positive: The conditional expectation $\mathrm{E}_{r}(\cdot, b)_{t}$ exceeds $\mathrm{E}\left(S_{T}, S_{t}, r, r^{f}, \sigma, \tau\right)_{t}=S_{t} \exp ^{\mu \tau}$, since reflection both prevents the exchange rate from falling below $b$ and reflects the exchange rate upwards at that value when compared with GBM. In other words, the barrier $b$ can only create additional conditional expectation and consequently $\Delta_{r}$ is negative for non-zero values of $b$. In this case, however, the exchange rate follows a submartingale and no longer a martingale, since a martingale must be both a submartingale and a supermartingale (Dooв, 1971). Risk-neutral valuation must then be justified by the NFLVR assumption (DELBAEN and SCHACHERMAYER, 1994) in order to prevent the arbitrage opportunities that would otherwise arise when the martingale restriction is not fulfilled (LongstafF, 1995).

Both a larger time to maturity $\tau$ and a higher volatility level $\sigma$ (panels 1 and 3 in Figure 1) make $\Delta_{r}$ more negative compared to the baseline scenario. Indeed, the reflection mechanism is superimposed on GBM, such that evaluating the difference in conditional expectations in Equation (14) isolates the effect of reflection. Consequently, both a larger time to maturity $\tau$ and a higher volatility $\sigma$ step up the likelihood of reflection and thus cause $\Delta_{r}$ to become more negative. Likewise, a higher domestic interest rate $r$ (panel 2 in Figure 1) reduces the likelihood that $b$ will be reached: For instance, according to uncovered interest parity, a higher risk-free interest rate differential between the domestic and the 
Figure 1: The Difference between the Two Put-Call Parities in the Case of Geometric Brownian Motion with Reflection.
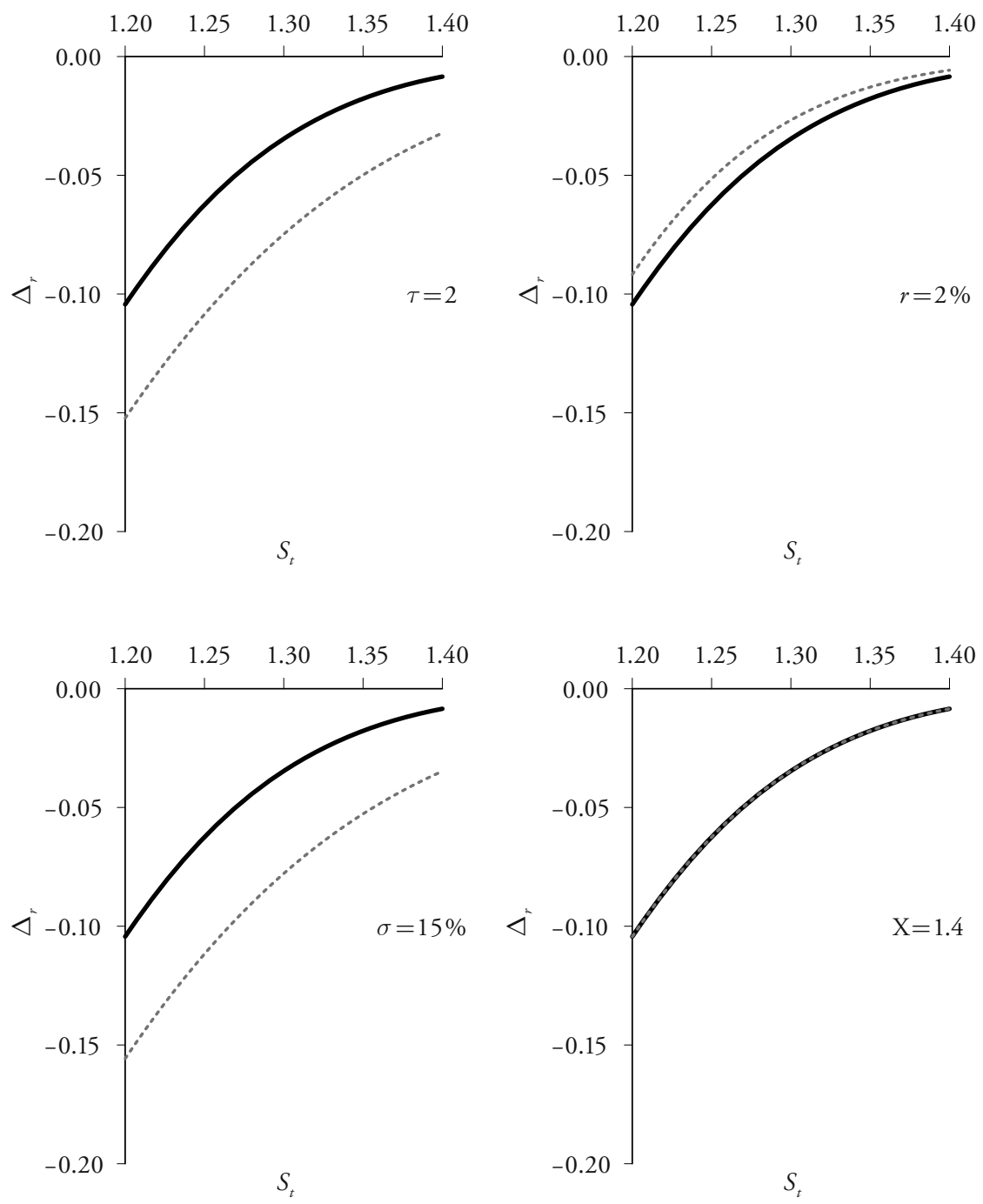

Notes: The figure shows the difference between the two put-call parities in the case of geometric Brownian motion with reflection $\left(\Delta_{r}\right)$ for the baseline scenario with $b=1.20, X=1.25, r=0.05 \%$, $r^{f}=1.05 \%, \sigma=10 \%$ and $\tau=1$ (solid lines) and for a scenario with higher values of the parameters $\tau, r, \sigma$ and $X$ (dotted lines). 
foreign country translates into an expected depreciation of the domestic currency vis-à-vis the foreign currency, whereby $S_{t}$ is expected to increase over time, such that the lower probability of $S_{t}$ hitting the lower barrier $b$ causes the difference to become less negative. Figure 1 reveals that $\Delta_{r}$ does not depend on the exercise price $X$ and therefore the lines in panel 4 coincide. At first sight, this may come as a surprise, given the prominent role of $X$ in Equations (11) and (12). However, Equation (14) shows that $\Delta_{r}$ yields a probabilistic interpretation in terms of conditional expected values and therefore does not depend on the exercise price $X$.

Imputing the call price via the risk-neutral put price and using the standard put-call parity in a risk-neutral pricing framework yields

$$
C_{r}^{P C P}(\cdot, b)_{t} \equiv C_{r}^{P C P}\left(X, S_{t}, r, r^{f}, \sigma, \tau, b\right)_{t}=P_{r}(\cdot, b)_{t}-P C P .
$$

Similarly, imputing the put price via the risk-neutral call price and using the standard put-call parity in a risk-neutral pricing framework yields

$$
P_{r}^{P C P}(\cdot, b)_{t} \equiv P_{r}^{P C P}\left(X, S_{t}, r, r^{f}, \sigma, \tau, b\right)_{t}=C_{r}(\cdot, b)_{t}+P C P .
$$

As $\Delta_{r}$ is non-positive, this implies that the imputed call price $C_{r}^{P C P}(\cdot, b)_{t}$ is too low compared to the corresponding risk-neutral call price $C_{r}(\cdot, b)_{t}$, and that the imputed put price $P_{r}^{P C P}(\cdot, b)_{t}$ is too high compared to the corresponding riskneutral put price $P_{r}(\cdot, b)_{t}$, since:

$$
\begin{aligned}
\Delta_{r} & =P_{r}(\cdot, b)_{t}-C_{r}(\cdot, b)_{t}-P C P, \\
& =C_{r}^{P C P}(\cdot, b)_{t}-C_{r}(\cdot, b)_{t}, \\
& =P_{r}(\cdot, b)_{t}-P_{r}^{P C P}(\cdot, b)_{t} \leq 0 .
\end{aligned}
$$

Notice that although, for instance, the call option can be sold short and replicated (using the standard PCP), this investment strategy is not admissible under the NFLVR assumption, since it risks unbounded losses before unwinding the short position. 


\section{A Cautionary Note and an Empirical Application: Foreign Exchange Hedging Costs under the SNB's Minimum Exchange Rate Policy}

\subsection{Motivation}

In this section, the impact that the introduction of a lower reflecting barrier has on FX hedging costs for an exchange rate that previously followed a GBM in a free-floating exchange rate system is analyzed. For consistency reasons, it is assumed that after the announcement of a minimum exchange rate for the domestic currency vis-à-vis a specific foreign currency, or when there is in effect a temporary ${ }^{13}$ unilateral one-sided target zone in place (i.e., there is a strongside commitment to support one currency vis-à-vis another currency), that the exchange rate follows a RGBM.

To be more specific and as already mentioned in Section 1, in this section the EUR/CHF exchange rate is used and the time period from September 6, 2011 to January 15, 2015 is analyzed, i.e., the period when the SNB had a minimum exchange rate policy vis-à-vis the euro currency in place. Assuming that in this period the Swiss franc vis-à-vis the euro followed a RGBM, the continuous-time analogue of a Gaussian random walk with drift and a reflecting barrier for the exchange rate, the impact that the introduction of the EUR/CHF 1.20 floor has had on FX hedging costs can be analyzed.

The FX hedging costs are modeled by a risk reversal strategy for the EUR/ $\mathrm{CHF}$ exchange rate, which is a strategy that is derived from the standard putcall parity and consists of a long European out-of-the-money EUR put/CHF call option (which corresponds to an EUR/CHF put) and a short European outof-the-money EUR call/CHF put option (which corresponds to an EUR/CHF call), both with the same time to maturity and identical option delta in absolute value. The underlying plain vanilla options allow, for instance, the buyer of the EUR/CHF put (call) option to sell (buy) the euro currency in exchange for the Swiss franc at the maturity date.

This risk reversal strategy implies a bearish view concerning the euro currency (Dunis and LeQueux, 2001), since positive risk reversal prices imply that investors sought protection against a strengthening Swiss franc (or a weakening of the euro currency) in the period analyzed. Hence, risk reversals proxy the costs

13 Dumas and Svensson (1994) and Broome (2001) analyze the expected lifetime of unilateral target zones and the factors that determine their survival time. It may be interesting to analyze the recent Swiss experience, which may add new insights to this strand of literature. 
associated with hedging exposure to the euro currency for investors who use the Swiss franc as their numéraire.

Notice that throughout the empirical application and according to the market practice, the risk reversal strategy involves put and call options with different exercise prices. Therefore, in the following, the exercise price for the put and call options is denoted by $X_{1}$ and $X_{2}$ with $X_{1}<X_{2}$, respectively. The exercise prices for both option contracts can be easily recovered from the price quotes via the option's delta (see, for instance Castagna and Mercurio (2005) for the exact formulas to obtain the option delta).

\subsection{Data}

To calculate the impact of introducing a minimum exchange rate on FX hedging costs, the required continuously compounded domestic and foreign risk-free interest rates $r$ and $r^{f}$ are proxied by the corresponding CHF LIBOR and EUR LIBOR interest rates for a contract maturity of 3 months. In order to specify the volatility level $\sigma$, option implied volatilities for call and put options on the EURCHF spot FX rate from Bloomberg with a "delta" of $\Delta \pm 25 \%$ and at-the-money delta neutral options with a contract maturity of 3 months are used, covering the period from September 6, 2011 to January 14, 2015. Specifically, it is assumed that investors use the previous day's implied volatility as an estimate for today's implied volatility, following Whaley (1993) and BaKshi, CaO, and Chen (1997), among others, as compared to alternative measures, this procedure has a large forecasting power (see, e.g., SATChell (2007) and WANG and DAigler (2011)). The volatility smile effect is captured by applying the Vanna-Volga approximation as discussed in Castagna and Mercurio (2005), thereby getting implied volatilities $\sigma^{V V}$ that are consistent with the previous day's volatility smile curve. ${ }^{14}$ The required spot EUR/CHF exchange rate is obtained from Bloomberg as well.

Notice that under the SNB's minimum exchange rate regime, EUR/CHF put options with strike prices below the EUR/CHF 1.20 floor should have traded at a price equal to zero. During this period, however, some of these contracts traded at non-zero costs in the market (Hertrich and Zimmermann, 2015). Therefore, under the RGBM framework of this paper, a floor level $b<$ EUR/ CHF 1.20 that is consistent with these put option prices is required, whereby some investors expected a realignment of the floor to a lower level. The prices for the risk reversal strategies in Subsection 2.3 can then be estimated using the

14 More details about the Vanna-Volga method can be found in, e.g., Castagna and Mercurio (2005), Castagna and Mercurio (2007), Wystup (2010b) or Bossens et al. (2010). 
implied EUR/CHF floor levels $b$ from Hertrich and Zimmermann (2015), which are estimated using the same EUR/CHF put options than in this paper and are associated with the same Vanna-Volga implied volatilities $\sigma^{V V}$ for the EUR/CHF exchange rate. Moreover, assuming that in the period of interest call options were priced in the same way than put options, these implied floor levels can also be used for the EUR/CHF call options.

\subsection{Empirical Results}

In both regimes, the costs associated with a risk reversal strategy equal the difference between the put and call prices. As the introduction of a lower boundary has a positive effect on call prices (Veestraeten, 2008) and a negative effect on put prices (Hertrich and Zimmermann, 2015), it is expected that hedging costs decreased for investors who use the Swiss franc as their numéraire and hedged exposure to the euro in the period analyzed.

Accordingly, the estimated hedging costs in a risk-neutral pricing framework or the fundamental value (see Section 2.2) of this strategy $R R_{R N}$ are equal to the difference between the risk-neutral put prices $\sigma^{V V}, \tau, b_{t}$ and the risk-neutral call prices, where the Vanna-Volga implied volatilities $\sigma^{V V}$, the implied floor levels $b$ from Hertrich and Zimmermann (2015), the corresponding exercise prices (estimated as in Castagna and Mercurio (2005)), the spot EUR/CHF exchange rate and both the domestic and foreign risk-free interest rates from Bloomberg are used:

$$
R R_{R N} \equiv P_{r}\left(X_{1}, S_{t}, r, r^{f}, \sigma^{V V}, \tau, b\right)_{t}-C_{r}\left(X_{2}, S_{t}, r, r^{f}, \sigma^{V V}, \tau, b\right)_{t} .
$$

Before proceeding, however, it is necessary to relate the fact that two different no-arbitrage conditions arise when the diffusion is bounded to the empirical application in this section. As already mentioned, it can be shown that also in cases where the martingale property is lost, the put price is unique and equals the risk-neutral put price, whereas the same does not hold for call options, i.e., multiple call prices can arise and coexist, depending on the no-arbitrage condition involved (see Section 2.2). Hence, the hedging costs that are implied by using the same call exercise prices than in Equation (18) and the standard put-call parity are denoted by $R R_{P C P}$ and equal the difference between the risk-neutral put price and the imputed call price:

$$
R R_{P C P} \equiv P_{r}\left(X_{1}, S_{t}, r, r^{f}, \sigma^{V V}, \tau, b\right)_{t}-C_{r}^{P C P}\left(X_{2}, S_{t}, r, r^{f}, \sigma^{V V}, \tau, b\right)_{t} .
$$


Finally, the hedging costs that are observed in the market are denoted by: ${ }^{15}$

$$
R R_{G K} \equiv P^{*}\left(X_{1}, S_{t}, r, r^{f}, \sigma^{m k t}, \tau\right)_{t}-C^{*}\left(X_{2}, S_{t}, r, r^{f}, \sigma^{m k t}, \tau\right)_{t},
$$

where $\sigma^{m k t}$ denotes the implied volatility level that accords with the observed option prices in the market using the GK model.

The estimated hedging costs or the prices of the analyzed risk reversal strategy are plotted in the following figure:

Figure 2: Three Different Pricing Methodologies for a EUR/CHF 3-Month 25-Delta

\section{Risk Reversal.}

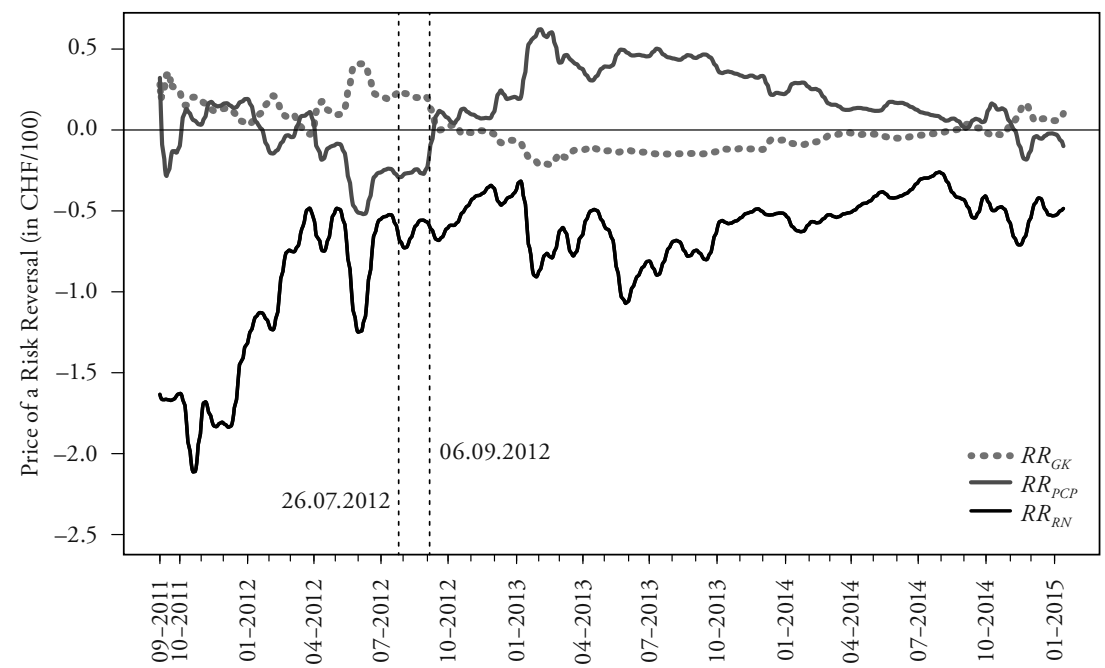

Notes: The figure plots the (smoothed using splines) prices (in CHF/100) of a EUR/CHF 3-month 25-delta risk reversal, from September 06, 2011 to January 14, 2015, based on the Garman-Kohlhagen currency pricing model, $R R_{G K}$, the price based on the standard put-call parity, $R R_{P C P}$ and the price in a risk-neutral pricing framework, $R R_{R N}$. Note that for graphical convenience, the y-axis has been scaled by dividing the risk reversal prices by 100 . The first marked date (26.07.2012) refers to the announcement of the "Draghi put" ("Whatever it takes"), the second marked date (06.09.2012) to the date when the European Central Bank launched the Outright Monetary Transaction (OMT) program. Data source: Bloomberg.

15 Notice that by market convention, the quoted FX market prices are the prices that arise when using the currency option pricing model developed by Garman and KoHLhagen (1983). 
Depending on the pricing methodology that is used, the prices of the analyzed hedging strategy fluctuated between $-0.0243 \mathrm{CHF}$ and approximately 0.0069 $\mathrm{CHF}$ in the period analyzed. According to the market prices $R R_{G K}$, the hedging costs were initially (mainly) positive and remained high for investors who use the Swiss franc as their numéraire and hedged exposure to the euro currency during the first quarters after the introduction of the EUR/CHF 1.20 floor. This means that market participants initially considered the risk of a depreciation of the euro currency as riskier than the risk of an appreciation of the euro currency (since $\left.R R_{G K}>0\right)$ and therefore sought protection against a weakening of the euro currency. It can also be seen that several episodes, such as, for example, the Greek and French elections in spring 2012 caused the EUR/CHF hedging costs to rise. From October 16, 2012 until October 30, 2014 these costs turned slightly negative, meaning that in this period investors rather sought protection against a strengthening of the euro currency vis-à-vis the Swiss franc. This observation is in line with the dynamics of the spot EUR/CHF exchange rate in Figure $\mathrm{C} 1$ in Appendix C. Apparently, the euro currency appreciated vis-à-vis the Swiss franc in the aftermath of the announcement of the details of the unlimited bond buying program by the president of the European Central Bank (ECB) Mario Draghi on September 6, 2012. Finally, in summer 2014, the costs of the analyzed hedging strategy turned less negative and fluctuated around a price of zero Swiss francs and finally became positive from October 31, 2014 onwards.

The costs for the fundamental value $R R_{R N}$, however, remained negative throughout the period analyzed. According to these prices, market participants viewed the risk of an appreciation of the euro currency as riskier than the risk of an depreciation of the euro currency (since $R R_{R N}<0$ ). The dynamics of $R R_{R N}$ contrasts the dynamics of $R R_{G K}$ and implies that the market prices significantly deviated from the fundamental values in the period analyzed, which may reflect the negative impact of the euro zone crisis on the euro currency, in the sense that investors overreacted to this crisis searching protection against a weakening of the euro currency that does not accord with the economic fundamentals of the euro currency. Interestingly, the speech of the president of the ECB on September 6, 2012 had no significant effect on these costs.

Notice that the different sign between the prices of the analyzed risk reversal strategy according to the different methodologies can indicate even opposed views: As the risk reversal is a measure of the skewness of the expected exchange rate distribution as of time $T$ (see Campa, Chang, and Reider (1998), among others), depending on which call price is used, the risk reversal $\left(R R_{G K}\right.$ or $\left.R R_{R N}\right)$ indicates either a bearish or a bullish view concerning the euro currency vis-àvis the Swiss franc. Therefore, risk reversals might have lost their relevance as a 
directional indicator of the expected EUR/CHF exchange rate movements under the SNB's minimum exchange rate regime.

As expected, ${ }^{16}$ the hedging costs $R R_{P C P}$ associated with the standard put-call parity are higher than the hedging costs $R R_{R N}$ that are derived from the riskneutral pricing framework. Moreover, the hedging costs $R R_{G K}$ that are observed in the market are closer to the hedging costs $R R_{P C P}$ than to $R R_{R N}$. This might indicate that the call price $C_{r}^{P C P}(\cdot, b)_{t}$ arose relatively more often than $C_{r}(\cdot, b)_{t}$, meaning that investors applied the standard put-call parity relatively more often than the risk-neutral parity. This accords with the observation in ProtTer (2013) who emphasizes that in financial markets the standard put-call parity most often holds, despite the fact that there are periods, e.g., during the dot.com bubble in the 1990s, where market prices violated the standard put-call parity in the presence of bubbles (see Lamont and Thaler (2003) and Ofek, Richardson, and Whitelaw (2004), among others). Also the fact that there are no restrictions on short selling EUR/CHF call options supports this view, since there are consequently no restrictions on admissible trading strategies.

Notice that the fact that under GBM with reflection more than one call price solves the Black-Scholes PDE adds uncertainty to FX markets, as it cannot be said which market price arises for call options, i.e., investors do not know whether $C_{r}(\cdot, b)_{t}$ or $C_{r}^{P C P}(\cdot, b)_{t}$ is the correct market price. This may cause investors to demand a risk premium on call options to compensate for the added uncertainty, which may depress call prices and might explain why the costs $R R_{P C P}$ were lower than the market prices of $R R_{G K}$ in the periods where the spot EUR/ $\mathrm{CHF}$ exchange rate was close to the EUR/CHF 1.20 floor, i.e., the periods from March 30, 2012 to September 6, 2012 and from October 31, 2014 onwards (see Figure 2 and Figure $\mathrm{C} 1$ in Appendix $\mathrm{C}$ ), since in these two periods the possibility of obtaining two different prices depending on the pricing methodology used became especially relevant (e.g., the risk-neutral call option price vs. the call option implied by the standard PCP), as $S_{t}$ was close to the EUR/CHF 1.20 floor and consequently the effect of the minimum exchange rate regime on the costs of the risk reversal strategy was more pronounced.

There is in fact a strand of literature that interprets the price difference between the model-implied option prices and the market prices as a risk premium, i.e., as a compensation for volatility risk or jump-size risk (see BALYEAT (2002) for a brief survey of this strand of literature). Therefore, although the introduction of the EUR/CHF 1.20 floor was successful in stabilizing the EUR/CHF exchange rate and positive for the Swiss macroeconomy (CHEN, 2012), the multiplicity of

16 Since $C_{r}^{P C P} \leq C_{r}$ according to Equation (17). 
call prices also implies that this policy might have had negative externalities in the form of additional costs associated with hedging FX risk associated with the Swiss franc vis-à-vis the euro, whereby during certain periods some investors may have been overexposed to FX risk.

All in all, the main picture is that hedging costs decreased substantially, but depending on the measure that is used, the period that is considered and which perspective is taken (i.e., whether the costs for investors who use the Swiss franc as their numéraire and hedge exposure to the euro currency or the costs for investors who use the euro as their numéraire and hedge exposure to the Swiss franc are considered), hedging costs remained high in a historical context. This conjecture is supported by Figure 3, where the hedging costs associated with the analyzed risk reversal strategy in the period from January 03, 2006 to September 05, 2011 before the SNB set the EUR/CHF 1.20 floor are plotted:

Figure 3: Market Price of a EUR/CHF 3-Month 25-Delta Risk Reversal.

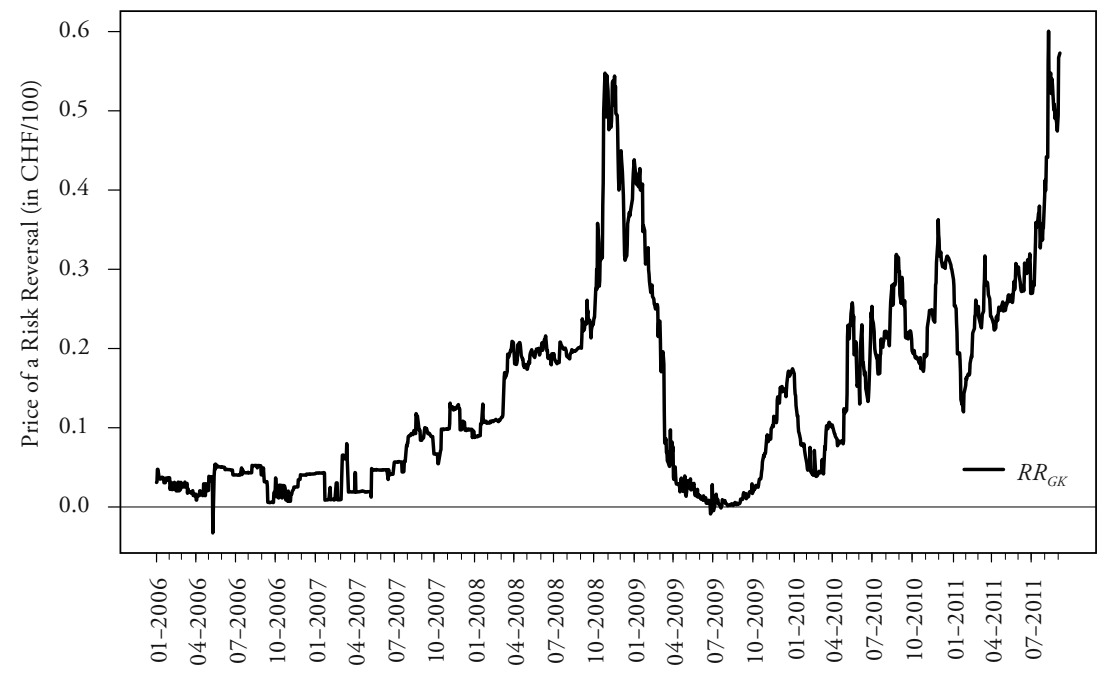

Notes: The figure plots the market price (in CHF/100) of a EUR/CHF 3-month 25-delta risk reversal, from January 03, 2006 to September 05, 2011, the day before the Swiss National Bank introduced the 1.20 EUR/CHF floor. The price is derived from the Garman-Kohlhagen currency pricing model and denoted by $R R_{G K}$. Note that for graphical convenience, the y-axis has been scaled by dividing the price by 100 . Data source: Bloomberg.

In a historical perspective, the recent Swiss experience entails periods where hedging costs vis-à-vis the euro were high, for instance, in the period from 
September 2011 to mid of December 2011 or from April 2012 to September 6, 2012 (Figure 2). In the latter period, for instance, hedging costs as measured by the market prices $R R_{G K}$ in Figure 2 fluctuate in the range between $0.0011 \mathrm{CHF}$ and approximately $0.0043 \mathrm{CHF}$, which is high compared to the hedging costs in the period before summer 2008 or from spring 2009 to spring 2011 (Figure 3). This is interesting, as under RGBM lower hedging costs are expected. A closer look at the parameters that have an impact on the difference between both parities and herewith on put and call prices (see Figure 1) might explain this observation, as the relatively high hedging costs (in a historical context) in part might reflect the narrowing of the interest rate differential between the 3-month CHF LIBOR interest rate and the 3-month EUR LIBOR interest rate until mid of December 2012 (Figure C2 in Appendix C), which then again modestly widened. This fact accords with panel 2 in Figure 1, whereby an increase in the interest rate differential goes hand-in-hand with a higher $\Delta_{r}$. Hence, the costs of a risk reversal strategy adjust accordingly.

\section{Conclusion}

The put-call parity, first formalized by STOLL (1969), which is referred to as the standard put-call parity in this paper, is based on a static hedge that results in a simple relationship between prices of European put and call options on the same underlying which share the same exercise price and time to maturity. Recent papers, however (see, for instance, Cox and Hobson (2005) and Heston, Loewenstein, and Willard (2007)), argue that the two parities differ when the martingale property is not fulfilled, such as in the case of an exchange rate that follows a reflected geometric Brownian motion (RGBM) in a minimum exchange rate regime.

This paper analyzes the relationship between the standard and the risk-neutral put-call parity for set-ups in which a reflecting barrier is superimposed on GBM. It is shown that the martingale property is no longer fulfilled when reflection is superimposed on GBM and that as a consequence, here also, the standard and the risk-neutral put-call parities differ. Given that there are studies in academia that in a risk-neutral pricing framework erroneously mix both parities using the traditional put-call parity as a shortcut to impute put (call) prices from call (price) prices when the diffusion is bounded by reflecting barriers, this paper shows that under RGBM the martingale restriction is not fulfilled and analyzes as a cautionary note the size and nature of the difference between both parities. Finally, the risk-neutral parity that is derived for a RGBM is used to analyze the impact 
that the introduction of a minimum exchange rate in an initially free-floating exchange rate system has on hedging costs (measured by a risk reversal strategy).

Using the EUR/CHF exchange rate in the period where the Swiss National Bank (SNB) had a minimum exchange rate regime for the euro currency vis-àvis the Swiss franc in place, this paper shows that in a historical context hedging costs were substantial (up to 0.0069 CHF) for investors who use the Swiss franc as their numéraire and sought protection against a weakening euro currency, contrary to the expected effect of introducing a one-sided target zone on these hedging costs. Consequently, some investors may have been overexposed to foreign exchange (FX) risk in the period analyzed. In addition, depending on the call price involved, the risk reversal strategy may even have indicated opposed views and might therefore have lost its relevance as a directional indicator of the expected EUR/CHF exchange rate movements under the SNB's minimum exchange rate regime. In addition and as a side effect of the main analysis, an alternative explanation for the existence of EUR/CHF put options with exercise prices below the EUR/CHF 1.20 floor that traded at non-zero cost in the period analyzed is offered, even if investors perceived the minimum exchange rate policy of the SNB vis-à-vis the euro currency as fully credible. It is shown that under RGBM such put options can indeed have positive prices, whenever investors in a risk-neutral pricing framework erroneously apply the standard putcall parity to impute put prices from call prices. This observation shows how, among others, risk-neutral investors can generate bubbles in derivatives markets, which may cause financial instability. Hence, the possibility of (at least theoretically) destabilizing price bubbles in FX markets also underlines the necessity of the present cautionary note.

\section{Appendix}

\section{A. The Conditional Expectation under GBM}

The conditional expectation under GBM with instantaneous reflection at the lower barrier $b$ gives:

$$
\begin{aligned}
\mathrm{E}_{r}\left(S_{T}, S_{t}, r, r^{f}, \sigma, \tau, b\right)_{t}= & S_{t} \exp ^{\mu \tau} \Phi\left(-z_{4}+\sigma \sqrt{\tau}\right)+b \Phi\left(z_{4}\right)+\frac{1}{\theta} \\
& \cdot\left\{S_{t} \exp ^{\mu \tau}\left(\frac{b}{S_{t}}\right)^{1+\theta} \Phi\left(z_{4}+\theta \sigma \sqrt{\tau}\right)-b \Phi\left(z_{4}\right)\right\},
\end{aligned}
$$


with $\mu=r-r^{f}$. Notice that $\mathrm{E}_{r}(\cdot, b)$ decreases to $\left\{S_{t} \cdot \exp ^{\mu \tau}\right\}$ for the limiting case of $b=0$ (i.e., for the case of GBM).

\section{B. Option Prices for $X<b$}

The risk-neutral call option price for $X<b$ is given by:

$$
\begin{aligned}
C_{r}\left(X, S_{t}, r, r^{f}, \sigma, \tau, b\right)_{t} & =\exp ^{-r \tau} \int_{b}^{\infty}\left(S_{T}-X\right) p r_{r}(\cdot, b) d S_{T}, \\
& =S_{t} \exp ^{-r^{f} \tau} \Phi\left(-z_{4}+\sigma \sqrt{\tau}\right)+b \exp ^{-r \tau} \Phi\left(z_{4}\right) \\
& +\frac{1}{\theta}\left\{\begin{array}{l}
S_{t} \exp ^{-r^{f} \tau}\left(\frac{b}{S_{t}}\right)^{1+\theta} \Phi\left(z_{4}+\theta \sigma \sqrt{\tau}\right) \\
-b \exp ^{-r \tau} \Phi\left(z_{4}\right)
\end{array}\right\} \\
& -X \exp ^{-r \tau} .
\end{aligned}
$$

Since $X<b$, reflection at $b$ implies that the exchange rate can never decrease below $X$. Consequently, the put option can never attain a positive value:

$$
P_{r}\left(X, S_{t}, r, r^{f}, \sigma, \tau, b\right)_{t}=0 .
$$

Notice that in this case the use of the standard put-call parity can generate positive put prices. Since $\Delta_{r}$ is non-positive, $P_{r}^{P C P}\left(X, S_{t}, r, r^{f}, \sigma, \tau, b\right)_{t}$ must be nonnegative (see Equation (17)). This may be an alternative explanation for the existence of EUR/CHF put options with exercise prices below the EUR/CHF 1.20 floor that traded at non-zero cost in the analyzed period, even if investors perceived the minimum exchange rate policy of the SNB vis-à-vis the euro as fully credible during the time to maturity. In other words, this means that investors might erroneously have applied the standard put-call parity in a risk-neutral pricing framework with the consequence that positive put prices arose. 


\section{Additional Figures}

Figure C1: Spot EUR/CHF Exchange Rate.

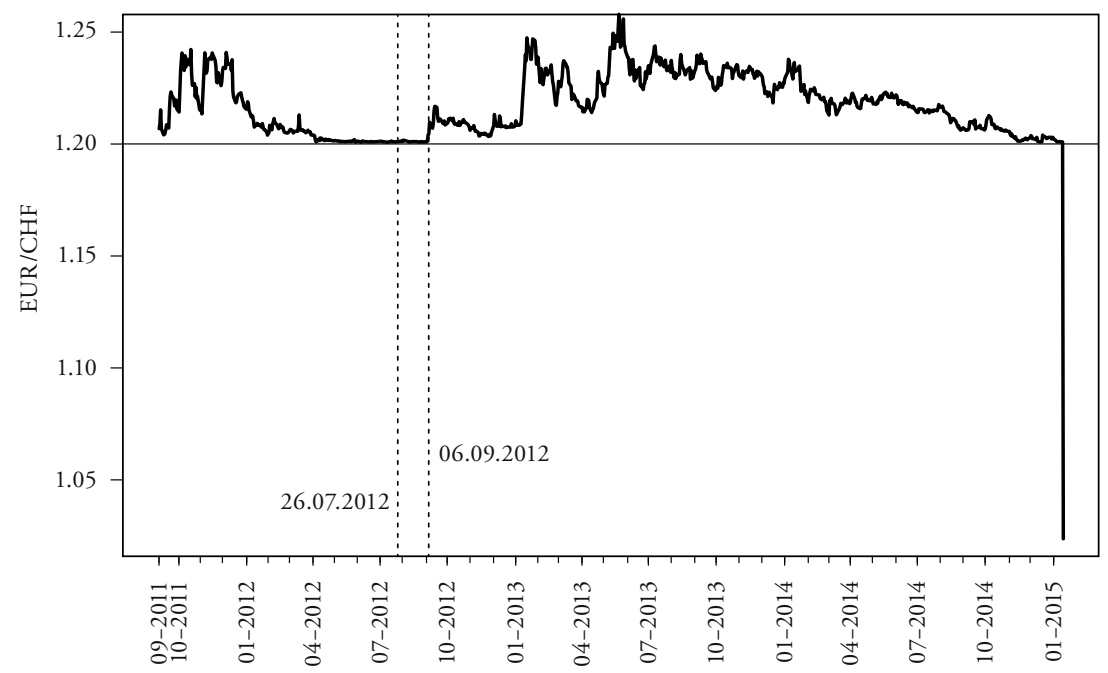

Notes: The figure plots the spot EUR/CHF exchange rate from September 06, 2011 to January 15, 2015. The first marked date (26.07.2012) refers to the announcement of the "Draghi put" ("Whatever it takes"), the second marked date (06.09.2012) to the date when the European Central Bank launched the Outright Monetary Transaction (OMT) program. Data source: Bloomberg.

Figure C2: The Risk-Free Interest Rate Differential between Switzerland and the Euro Zone.

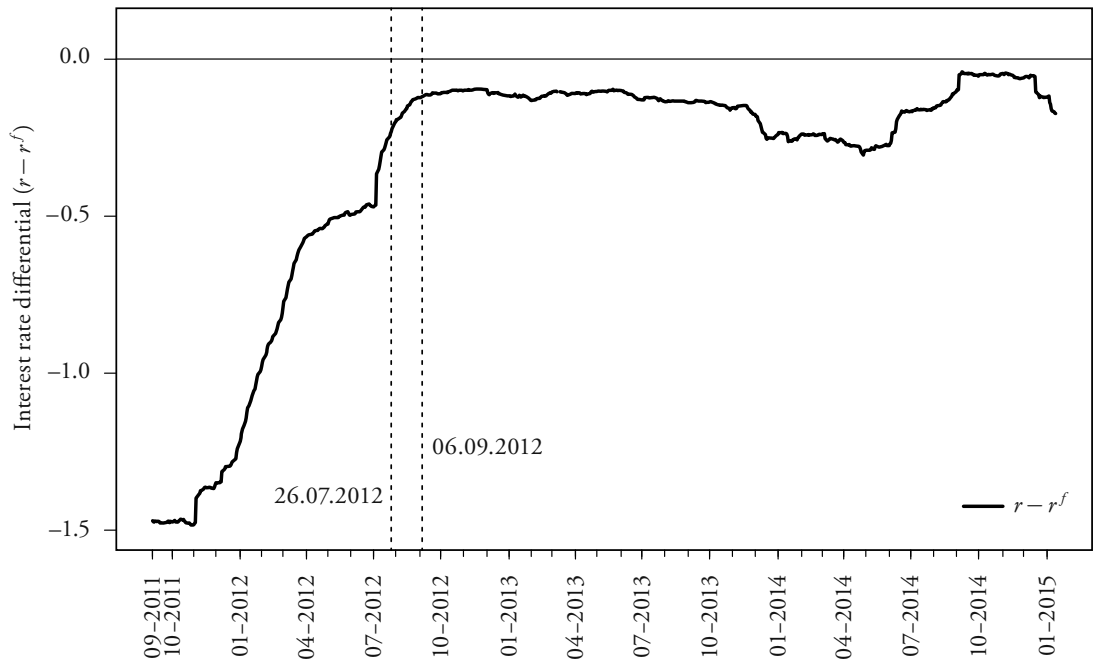


Notes: The figure plots the daily (annualized and continuously compounded) interest rate differential between the 3-month CHF LIBOR interest rate $(r)$ and the 3-month EUR LIBOR interest rate $\left(r^{f}\right)$ from September 06, 2011 to January 14, 2015. The first marked date (26.07.2012) refers to the announcement of the "Draghi put" ("Whatever it takes"), the second marked date (06.09.2012) to the date when the European Central Bank launched the Outright Monetary Transaction (OMT) program. Data source: Bloomberg.

\section{References}

Bakshi, Gurdip, Charles Cao, and Zhiwu Chen (1997), "Empirical Performance of Alternative Option Pricing Models", Journal of Finance, 52(5), pp. 2003-2049.

Balyeat, R. Brian (2002), "Economic Significance of Risk Premiums in the S\&P 500 Option Market", Journal of Futures Markets, 22(12), pp. 1147-1178.

Bergman, Yaacov Z. (1996), "Equilibrium Asset Price Ranges", International Review of Financial Analysis, 5(3), pp. 161-169.

Black, Fischer, and Myron Scholes (1973), "The Pricing of Options and Corporate Liabilities”, Journal of Political Economy, 81(3), pp. 637-654.

Bossens, Frédéric, Grégory Rayée, Nikos S. Skantzos, and Griselda Deelstra (2010), "Vanna-Volga Methods Applied to FX Derivatives: From Theory to Market Practice", International Journal of Theoretical and Applied Finance, 13(8), pp. 1293-1324.

Broome, Simon (2001), "The Lifetime of a Unilateral Target Zone: Some Extended Results", Journal of International Money and Finance, 20(3), pp. 419-438.

Campa, José M., and P.H. Kevin Chang (1996), "Arbitrage-Based Tests of Target-Zone Credibility: Evidence from ERM Cross-Rate Options”, American Economic Review, 86(4), pp.726-740.

Campa, José M., P.H. Kevin Chang, and Robert L. Reider (1998), "Implied Exchange Rate Distributions: Evidence from OTC Option Markets", Journal of International Money and Finance, 17(1), pp. 117-160.

Carr, Peter, Travis Fisher, and Johannes Ruf (2014), "On the Hedging of Options on Exploding Exchange Rates", Finance and Stochastics, 18(1), pp. 115-144.

Castagna, Antonio, and Fabio Mercurio (2005), "Consistent Pricing of FX Options", Internal Report, Banca IMI.

Castagna, Antonio and Fabio Mercurio (2007), "The Vanna-Volga Method for Implied Volatilities”, Risk Magazine, pp. 39-44. 
Chaboud, Allen P., and Owen F. Humpage (2005), "An Assessment of the Impact of Japanese Foreign Exchange Intervention: 1991-2004", International Finance Discussion Papers, 824, pp. 1-41.

Chen, Shunangshuang (2012), "The Implication of the Exchange Rate Floor in Current Times: The Swiss Experience”, University of California Working Paper, pp. 1-34.

Cottarelli, Carlo and Peter Doyle (1999), "Disinflation in Transition, 1993-97", International Monetary Fund Occasional Paper, 179, pp. 1-45.

Cox, Alexander M. G., and David G. Hobson (2005), "Local Martingales, Bubbles and Option Prices", Finance and Stochastics, 9(4), pp.477-492.

Cox, John C., and Stephen A. Ross (1976), "The Valuation of Options for Alternative Stochastic Processes", Journal of Financial Economics, 3(1), pp. 145-166.

Czech National Bank (2013), "7th Situation Report on Economic and Monetary Developments", in Press Release (November 7, 2013).

Delbaen, Freddy, and Walter Schachermayer (1994), "A General Version of the Fundamental Theorem of Asset Pricing", Mathematische Annalen, 300(1), pp. 463-520.

Delbaen, Freddy, and Walter Schachermayer (1998), “The Fundamental Theorem of Asset Pricing for Unbounded Stochastic Processes", Mathematische Annalen, 312(2), pp. 215-250.

Dhrymes, Phoebus J. (1998), Time Series, Unit Roots, and Cointegration, San Diego: Academic Press.

Dillén, Hans, and Peter Sellin (2003), "Financial Bubbles and Monetary Policy”, Sveriges Riksbank Economic Review, 3, pp. 119-144.

Dоoв, Joseph L. (1971), "What is a Martingale?", The American Mathematical Monthly, 78(5), pp. 451-463.

Dumas, Bernard, and Lars E. O. Svensson (1994), "How Long do Unilateral Target Zones Last?", Journal of International Economics, 36(3), pp. 467-481.

Dunis, Christian, and Pierre Lequeux (2001), "The Information Content of Risk Reversals", Derivatives Use, Trading, and Regulation, 7(2), pp. 98-117.

Eкström, Еriк, and Johan Tysк (2009), "Bubbles, Convexity and the BlackScholes Equation”, Annals of Applied Probability, 19(4), pp. 1369-1384.

Elworthy, K. David, Xue-Mei Li, and Marc Yor (1999), "The Importance of Strictly Local Martingales; Applications to Radial Ornstein-Uhlenbeck Processes", Probability Theory and Related Fields, 115(3), pp. 325-355.

Garman, Mark B., and Steven W. Kohlhagen (1983), "Foreign Currency Option Values", Journal of International Money and Finance, 2(3), pp. 231-237. 
Geman, Hélyette (2015), Agricultural Finance: From Crops to Land, Water and Infrastructure, Chichester: John Wiley \& Sons.

Gerber, Hans U. and Gérard Pafumi (2000), "Pricing Dynamic Investment Fund Protection", North American Actuarial Journal, 4(2), pp. 28-37; Discussion pp. 37-41.

Glasserman, Paul (2004), Monte Carlo Methods in Financial Engineering, Heidelberg: Springer.

Grabbe, J. Orlin (1983), "The Pricing of Call and Put Options on Foreign Exchange", Journal of International Money and Finance, 2(3), pp. 239-253.

Hanke, Michael, Rolf Poulsen, and Alex Weissensteiner (2015), "Where Would the EUR/CHF Exchange Rate be Without the SNB's Minimum Exchange Rate Policy?”, Working Paper, forthcoming in the Journal of Futures Markets.

Harrison, J. Michael (1985), Brownian Motion and Stochastic Flow Systems, reprint 1990 edn., New York: John Wiley \& Sons.

Hertrich, Markus, and Dirk Veestraeten (2013), "Valuing Stock Options when Prices are Subject to a Lower Boundary: A Correction", Journal of Futures Markets, 33(9), pp. 889-890.

Hertrich, Markus, and Heinz Zimmermann (2015), "On the Credibility of the Euro/Swiss Franc Floor: A Financial Market Perspective”, Working Paper, available at SSRN 2290997.

Heston, Steven L., Mark Loewenstein, and Gregory A. Willard (2007), "Options and Bubbles", Review of Financial Studies, 20(2), pp.359-390.

Humpage, Owen F., and Javiera Ragnartz (2006), "Swedish Intervention and the Krona Float, 1993-2002", Sveriges Riksbank Working Paper Series, 192, pp. 1-40.

Imai, Junichi, and Phelim P. Boyle (2001), “Dynamic Fund Protection”, North American Actuarial Journal, 5(3), pp. 31-49; Disscussion pp.49-51.

Ingersoll Jr., Jonathan E. (1987), Theory of Financial Decision Making, Totowa: Rowman \& Littlefield.

Ingersoll JR., Jonathan E. (1997), "Valuing Foreign Exchange Rate Derivatives with a Bounded Exchange Process", Review of Derivatives Research, 1(2), pp. $159-181$.

Jarrow, Robert A., and Philip Protter (2007), "An Introduction to Financial Asset Pricing", in Handbooks in Operations Research and Management Science, vol. 15, chap. 1, pp. 13-69, Amsterdam: North-Holland.

Jarrow, Robert A., and Philip Protter (2011), "Foreign Currency Bubbles", Review of Derivatives Research, 14(1), pp. 67-83. 
Jarrow, Robert A., Philip Protter, and Kazuhiro Shimbo (2007), "Asset Price Bubbles in Complete Markets", in Advances in Mathematical Finance, Michael C. Fu, Robert A. Jarrow, Ju-Yi J. Yen, and Robert J. Elliott, eds., pp. 97-121, Basel: Birkhäuser Verlag.

Jarrow, Robert A., Philip Protter, and Kazuhiro Shimbo (2010), "Asset Price Bubbles in Incomplete Markets", Mathematical Finance, 20(2), pp. 145-185.

Jermann, Urban J. (2015), "Financial Markets' Views about the Euro-Swiss Franc Floor”, Working Paper, available at SSRN 2490086.

Ko, Bangwon, Elias S.W. Shiu, and Li Wei (2010), "Pricing Maturity Guarantee with Dynamic Withdrawal Benefit", Insurance: Mathematics and Economics, 47(2), pp. 216-223.

Lamont, Owen A., and Richard H. Thaler (2003), "Can the Market Add and Subtract? Mispricing in Tech Stock Carve-outs", Journal of Political Economy, 111(2), pp. 227-268.

Longstaff, Francis A. (1995), "Option Pricing and the Martingale Restriction", Review of Financial Studies, 8(4), pp. 1091-1124.

Maccioni, Alessandro Fiori (2011), "Endogenous Bubbles in Derivatives Markets: The Risk Neutral Valuation Paradox", Working Paper, University of Sassari.

Madan, Dilip B., and Marc Yor (2006), "Ito's Integrated Formula for Strict Local Martingales", in In Memoriam Paul-André Meyer, pp. 157- 170, Heidelberg: Springer.

Merton, Robert C. (1973), "Theory of Rational Option Pricing”, Bell Journal of Economics and Management Science, 4(1), pp. 141-183.

Musiela, Marek, and Marek Rutkowski (2009), Martingale Methods in Financial Modelling, Heidelberg: Springer.

Ofek, Eli, Matthew Richardson, and Robert F. Whitelaw (2004), "Limited Arbitrage and Short Sales Restrictions: Evidence from the Options Markets", Journal of Financial Economics, 74(2), pp.305-342.

Pennacchi, George (2008), Theory of Asset Pricing, Boston: Pearson Education. Protter, Philip (2013), "A Mathematical Theory of Financial Bubbles", in Paris-Princeton Lectures on Mathematical Finance 2013, Vicky Henderson and Ronnie Sircar, eds., vol. 2081 of Lecture Notes in Mathematics, pp. 1-108, Heidelberg: Springer.

Reiswich, Dimitri, and Uwe Wystup (2010), "A Guide to FX Options Quoting Conventions", Journal of Derivatives, 18(2), pp. 58-68.

Ruf, Johannes (2013), “Negative Call Prices”, Annals of Finance, 9(4), pp. 787-794. 
Satchell, Stephen (2007), Forecasting Expected Returns in the Financial Markets, London: Academic Press.

Shiller, Robert J. (2000), "Measuring Bubble Expectations and Investor Confidence", Journal of Psychology and Financial Markets, 1(1), pp.49-60.

Shonkwiler, J. Scott, and Gangadharrao S. Maddala (1985), "Modeling Expectations of Bounded Prices: An Application to the Market for Corn", Review of Economics and Statistics, 67(4), pp. 697-702.

Skoroknod, Anatoliy V. (1961), "Stochastic Equations for Diffusion Processes in a Bounded Region", Theory of Probability and its Applications, 6(3), pp. 264-274.

Stoll, Hans R (1969), "The Relationship Between Put and Call Option Prices", Journal of Finance, 24(5), pp. 801-824.

Swiss National Bank (2011), „Nationalbank legt Mindestkurs von 1.20 Franken pro Euro fest", in Press Release (September 6, 2011).

Veestraeten, Dirk (2008), "Valuing Stock Options when Prices are Subject to a Lower Boundary”, Journal of Futures Markets, 28(3), pp. 231-247.

Veestraeten, Dirk (2013), "Currency Option Pricing in a Credible Exchange Rate Target Zone”, Applied Financial Economics, 23(11), pp. 951-962.

Wang, Zhiguang, and Robert T. Daigler (2011), "The Performance of VIX Option Pricing Models: Empirical Evidence Beyond Simulation”, Journal of Futures Markets, 31(3), pp. 251-281.

Whaley, Robert E. (1993), "Derivatives on Market Volatility: Hedging Tools Long Overdue", Journal of Derivatives, 1(1), pp.71-84.

Wystup, Uwe (2010a), "Foreign Exchange Symmetries", in Encyclopedia of Quantitative Finance, Rama Cont, ed., vol. 2, pp. 752-759, Chichester: John Wiley \& Sons.

Wystup, Uwe (2010b), "Vanna-Volga Pricing", in Encyclopedia of Quantitative Finance, Rama Cont, ed., vol.4, pp. 1867-1874, Chichester: John Wiley \& Sons.

\section{SUMMARY}

The put-call parity is free from distributional assumptions. It is tempting to assume that this parity also holds when an asset pricing model includes reflecting barriers. This paper shows that in the case of geometric Brownian motion with reflection such barriers cause the standard put-call parity to differ from the riskneutral parity. This paper then analyzes the error that arises when the diffusion is bounded and the standard put-call parity is applied in a risk-neutral framework 
as a shortcut to impute put prices from call prices, and vice versa. The risk-neutral parity that is derived for a reflected geometric Brownian motion is then used to analyze the impact that the Swiss National Bank's minimum exchange rate regime vis-à-vis the euro has had on foreign exchange hedging costs. The analysis shows that in the analyzed period domestic investors may have incurred substantial costs as a result of hedging exposure to the euro currency and may have been overexposed to foreign exchange risk. 